\title{
Polystyrene-polysiloxane Diblock Copolymer having Liquid Crystalline Side Chains
}

\author{
Tomoe Tanaka, ${ }^{\dagger}$ Tomohiro Yorisue, ${ }^{\ddagger}$ Hiroyuki Hanahata, ${ }^{\ddagger}$ Motonori Komura, ${ }^{\S}$ \\ Hirohisa Yoshida and Sadayuki Asaoka ${ }^{\dagger, *}$ \\ ${ }^{\dagger}$ Department of Biomolecular Engineering, Kyoto Institute of Technology, Matsugasaki, Kyoto 606-8585, Japan. \\ ${ }^{\ddagger}$ Asahi Kasei E-Materials Corporation, 2-1 Samejima, Fuji-shi, Shizuoka 416-8501, Japan. \\ ${ }^{\S}$ Chemical Resources Laboratory, Tokyo Institute of Technology, 4259 Nagatsuta-cho, Midori-ku, Yokohama \\ 226-8503, Japan. \\ "Division of Applied Chemistry,Faculty of Urban Environmental Sciences, Tokyo Metropolitan University, 1-1 \\ Minamiohsawa, Hachioji 192-0397, Japan. \\ TEL\&Fax: +81-75-724-7768, E-mail: sada@kit.ac.jp
}

The polystyrene- $b$-poly(vinyl methylsiloxane) (PS- $b$-PVMS) main chain was synthesized via the anionic polymerization of styrene and cyclotrisioxane momomer consecutively. The catalytic hydrosililation of vinyl groups with the hydrodisiloxane tethered by liquid crystalline stilbene mesogen unit afforded a diblock copolymer PS- $b$-PMS(Stb) with the narrow polydispersity $\left(M_{\mathrm{N}}=52100, M_{\mathrm{W}} / M_{\mathrm{N}}=1.25\right)$. This diblock copolymer exhibited liquid crystalline phase, and gave a lamellae-like nanostructure in the thin film thermally annealed at higher temperature than the isotropic-to-LC transition point.

Key words: polysiloxane, microphese segregated nanostructure, liquid crystalline polymer

\section{INTRODUCTION}

To create well-defined nanopatterns over large areas, a variety of patterning technologies including top-down and bottom-up methods have been developed. Fabrication of well-defined nanostructures for nanopatterning using the phase segregated nanostructure of block copolymers (BCPs) have been intensively studied because of the tunable dimensions and chemical properties with a flexible, simple, and low-cost process. Since the durability of polysiloxane upon reactive ion etching is considerably higher than conventional organic polymer such as polystyrene (PS), the diblock copolymer having a polysiloxane segment like PS- $b$-PDMS[1, 2] have been investigated for the purpose of application to the etching masks. Hayakawa et al. have reported that the block copolymers composed of polymethacrylate with polyoligomeric silsesquioxane (POSS) in the side chain affords highly ordered lamellae and/or cylindrical nanostructure in the thin film,[3] which can be used as the BCP mask to fabricate the line and/or dot patterns on the substrate.

We have already reported the amphiphilic diblock copolymer having liquid crystalline side chains, which gave normally oriented cylindrical phase segregated nanostructure along with the direction of mesogen arrangement in the thin film. $[4,5]$ The side-chain LC block copolymers composed of a polysiloxane segment have also been synthesized to improve the regularity of the phase segregated nanostructures.[6-9] We wish to report here about the synthesis and nanostructure of polystyrene-polysioxane diblock copolymer having liquid crystalline side chains with stilbene mesogens, which can be photo-closslinked upon UV-light irradiation to fix the nanostructure (PS- $b$-PMS(Stb)).

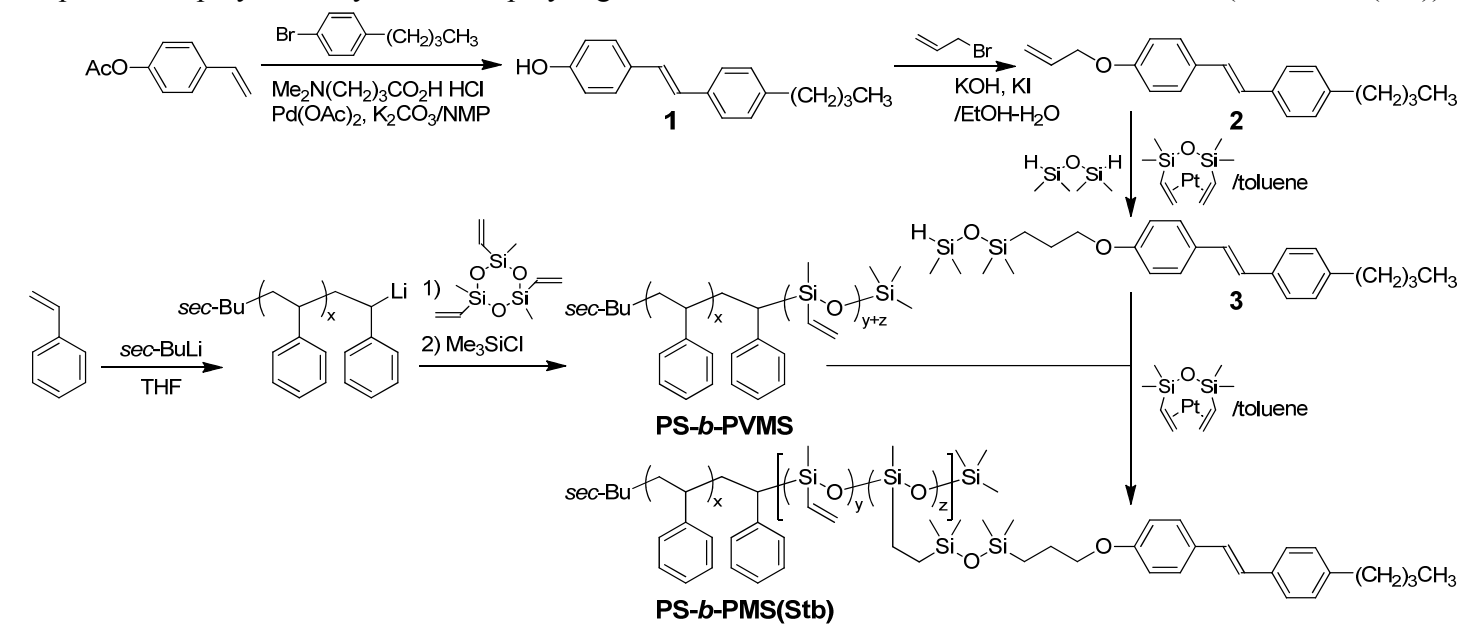

Scheme 1 Synthesis of polystyrene-polysiloxane diblock copolymer having LC side chains. 


\section{EXPERIMENTAL SECTION}

2.1 General

${ }^{1} \mathrm{H}$ NMR spectra were obtained on AV-300 spectrometers in chloroform-d. Molecular weights of polymers were determined by gel permeation chromatography (GPC) eluted by THF on a LF-804 column (Shodex) in reference of a series of standard polystyrene using a JASCO liquid chromatography system composed of a PU-980 HPLC pump and an 860-CO column oven (operated at $40{ }^{\circ} \mathrm{C}$ ) equipped with an ERMA ERC-8710 UV and a Shodex RI-101 RI detector. Thermal analyses were conducted under $\mathrm{N}_{2}$ flow on an SII DSC-6200 DSC system (Seiko Instruments Inc.) at a scanning rate of $5{ }^{\circ} \mathrm{C} / \mathrm{min}$. Temperature-dependent polarized optical microscopic (POM) observation was conducted under Ar flow by using an Olympus BX53 microscope fitted with a Imoto Machinery Co., Ltd. thermo-control system. Small-angle X-ray scattering (SAXS) measurements were carried out at the beamline $10 \mathrm{C}$ in Photon Factory, High Energy Accelerator Research Organization (Tsukuba, Japan), by using a one-dimensional positionsensitive proportional counter (Rigaku) as a detector. Transmission electron microscope (TEM) images were obtained by using a Hitachi H-7100 electron microscope at an acceleration voltage of $100 \mathrm{kV}$. The samples for observation were prepared subject to the following procedure. The spin-coated films from the $2 \mathrm{wt} \%$ toluene solutions of the block copolymers on the fresh surface of mica substrates were annealed above the isotropic transition temperature under vacuum without any precise control of the heating and cooling rate. The obtained thin films were easily peeled from the substrates by soaked in water, and then transferred onto copper grids.

\subsection{Materials}

After treated with $2 \%$ sodium hydroxide aqueous solution, styrene was freshly distilled under reduced pressure once from calcium hydride and then from isopropylmagnesium chloride just prior to use. 1,3,5-trimethyl-1,3,5-trivinylcyclotrisiloxane purchased from Shinetsu was vacuum distilled from the calcium hydride. THF used for the anion polymerization was freshly distilled once from sodium containing benzophenone, and then from butyllithium just prior to use. $N$-methylpyrrolidone was distilled under reduced pressure from the calcium hydride. Toluene was distilled from melting sodium containing benzophenone. All other chemicals were used as purchased without further purification.

(E)-4-(4-Butylstyryl)phenol (1). The NMP $(50 \mathrm{~mL})$ solution of 4-vinylphenylacetate $(12.7 \mathrm{~g}, 78.3 \mathrm{mmol})$, 1-bromo-4-butylbenzene $(11.5 \mathrm{~g}, 54.0 \mathrm{mmol})$, $\mathrm{Me}_{2} \mathrm{~N}\left(\mathrm{CH}_{2}\right)_{3} \mathrm{CO}_{2} \mathrm{H} \cdot \mathrm{HCl} \quad(10.2 \quad \mathrm{mg}, 60.8 \mu \mathrm{mol})$, palladium acetate $(15.4 \mathrm{mg}, 68.6 \mu \mathrm{mol})$ and potassium carbonate $(28.2 \mathrm{~g}, 204 \mathrm{mmol})$ was stirred at $130^{\circ} \mathrm{C}$ for $24 \mathrm{~h}$ under nitrogen atmosphere. The mixture was diluted $\mathrm{CH}_{2} \mathrm{Cl}_{2}$, and washed with water, $1 \mathrm{~N} \mathrm{HCl}$ and brine. The organic layer dried over $\mathrm{Na}_{2} \mathrm{SO}_{4}$ and the solvent was removed under reduced pressure. The crude product was purified on the silica gel column chromatography by using hexane-ethyl acetate $(5: 1)$ as eluent, followed by recrystallization in methanol, to give colorless needles $(8.1 \mathrm{~g}, 59 \%) .{ }^{1} \mathrm{H} \mathrm{NMR}\left(\mathrm{CDCl}_{3}\right)$ $\delta 7.40(\mathrm{~d}, J=8.4 \mathrm{~Hz}, 4 \mathrm{H}), 7.16(\mathrm{~d}, J=8.1 \mathrm{~Hz}, 2 \mathrm{H})$, $6.97(\mathrm{~d}, J=7.0 \mathrm{~Hz}, 2 \mathrm{H}), 6.82(\mathrm{~d}, J=8.4 \mathrm{~Hz}, 2 \mathrm{H}), 4.84$ $(\mathrm{s}, 1 \mathrm{H}), 2.61(\mathrm{t}, J=7.7 \mathrm{~Hz}, 2 \mathrm{H}), 1.63(\mathrm{t}, J=7.5 \mathrm{~Hz}$, $2 \mathrm{H}), 1.36(\mathrm{q}, J=7.5 \mathrm{~Hz}, 2 \mathrm{H}), 0.93(\mathrm{t}, J=7.3 \mathrm{~Hz}, 3 \mathrm{H})$.

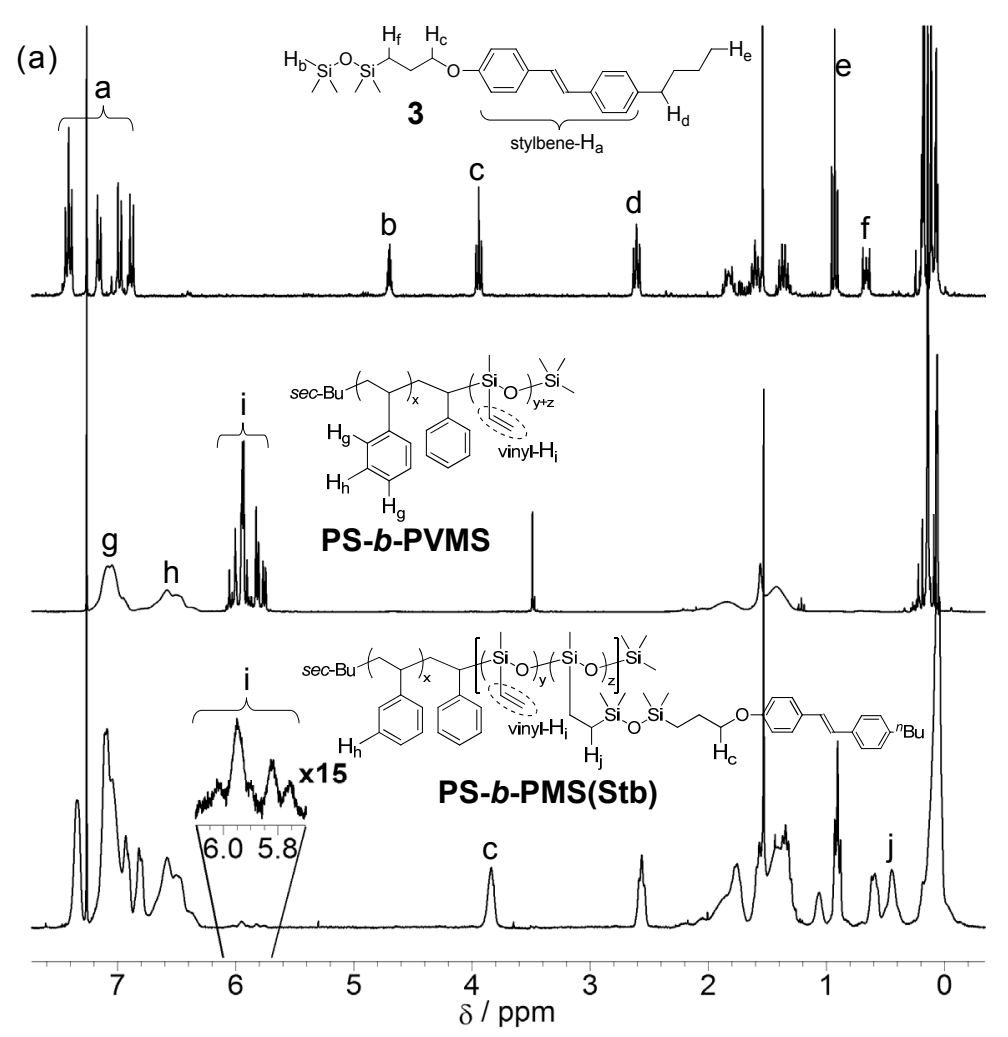

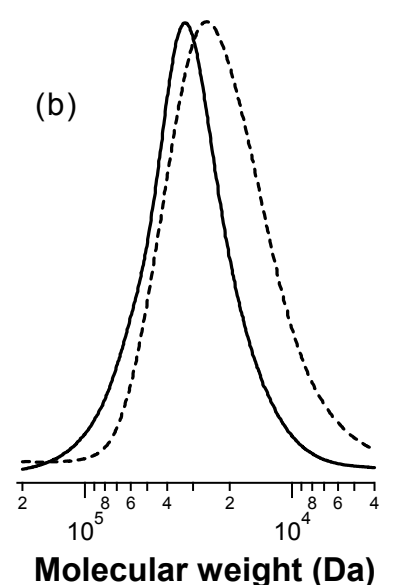

Figure 1 Synthesis of LC polystyrene-polysiloxane diblock copolymer by the combination of anionic polymerization and catalytic hydrosilylation. (a) ${ }^{1} \mathrm{H}$ NMR spectra of LC mesogen unit, back bone and diblock copolymer. (b) GPC profiles of the diblock copolymers, PS-b-PVMS (broken) and PS-b-PVMS(Stb) (full line). 
(E)-1-(Allyloxy)-4-(4-butylstyryl)benzene (2). A mixture of 1 (9.0 g, $36 \mathrm{mmol}$ ), potassium hydroxide (4.2 g, $75 \mathrm{mmol})$, potassium Iodide $(46 \mathrm{mg}, 280 \mu \mathrm{mol})$, allylbromide $(9.5 \mathrm{~g}, 78 \mathrm{mmol})$, ethanol $(300 \mathrm{~mL})$ and water $(15 \mathrm{~mL})$ was stirred at $60{ }^{\circ} \mathrm{C}$ for $4 \mathrm{~h}$ under nitrogen atmosphere. After removal of the solvent under reduced pressure, the residue was dissolved in $\mathrm{CH}_{2} \mathrm{Cl}_{2}$ and washed with water and brine. The organic layer was dried over $\mathrm{Na}_{2} \mathrm{SO}_{4}$ and the solvent was removed under reduced pressure. The crude product was recrystallized in ethanol, to give colorless powder (9.3 g, $89 \%) .{ }^{1} \mathrm{H}$ NMR $\left(\mathrm{CDCl}_{3}\right) \delta 7.42(\mathrm{t}, J=8.8 \mathrm{~Hz}$, 4H), $7.16(\mathrm{~d}, J=8.1 \mathrm{~Hz}, 2 \mathrm{H}), 6.98(\mathrm{~d}, J=6.9 \mathrm{~Hz}, 2 \mathrm{H})$, $6.91(\mathrm{~d}, J=8.8 \mathrm{~Hz}, 2 \mathrm{H}), 6.06(\mathrm{~m}, 1 \mathrm{H}), 5.42(\mathrm{~d}, J=$ $17.3 \mathrm{~Hz}, 1 \mathrm{H}), 5.30(\mathrm{~d}, J=10.5 \mathrm{~Hz}, 1 \mathrm{H}), 4.56(\mathrm{~d}, J=$ $5.3 \mathrm{~Hz}, 2 \mathrm{H}), 2.61(\mathrm{t}, J=7.7 \mathrm{~Hz}, 2 \mathrm{H}), 1.60(\mathrm{t}, J=7.7$ $\mathrm{Hz}, 2 \mathrm{H}), 1.36$ (q, $J=7.5 \mathrm{~Hz}, 2 \mathrm{H}), 0.93$ (t, $J=7.3 \mathrm{~Hz}$, $3 \mathrm{H})$.

(E)-1-(3-(4-(4-Butylstyryl)phenoxy)propyl)-1,1,3,3tetramethyldisiloxane (3). To the toluene $(40 \mathrm{~mL})$ solution of 1,1,3,3-tetramethyldisiloxane ( $40 \mathrm{~mL}, 227$ mmol), the mixture of $\mathbf{2}(6.5 \mathrm{~g}, 22 \mathrm{mmol})$ and platinum(0)-1,3-divinyl-1,1,3,3-tetramethyldisiloxane in xylene $(2.2 \%, 0.6 \mathrm{~mL}, 35 \mu \mathrm{mol})$ in toluene $(160$ $\mathrm{mL}$ ) was added dropwise and heated at $60{ }^{\circ} \mathrm{C}$ for $20 \mathrm{~h}$ under nitrogen atmosphere. After removal of the solvent under reduced pressure, the residue was purified on the silica gel column chromatography by using hexane-chloroform $(1: 1)$ as eluent, to yield colorless powder $(7.7 \mathrm{~g}, 81 \%)$. ${ }^{1} \mathrm{H}$ NMR $\left(\mathrm{CDCl}_{3}\right) \delta$ $7.41(\mathrm{t}, J=8.1 \mathrm{~Hz}, 4 \mathrm{H}), 7.16(\mathrm{~d}, J=8.1 \mathrm{~Hz}, 2 \mathrm{H}), 6.98$ $(\mathrm{d}, J=8.4 \mathrm{~Hz}, 2 \mathrm{H}), 6.88(\mathrm{~d}, J=8.7 \mathrm{~Hz}, 2 \mathrm{H}), 4.70(\mathrm{~m}$, $1 \mathrm{H}), 3.94(\mathrm{t}, J=6.9 \mathrm{~Hz}, 2 \mathrm{H}), 2.61(\mathrm{t}, J=7.3 \mathrm{~Hz}, 2 \mathrm{H})$, $1.83(\mathrm{~m}, 2 \mathrm{H}), 1.61(\mathrm{t}, J=7.7 \mathrm{~Hz}, 2 \mathrm{H}), 1.37(\mathrm{~m}, 2 \mathrm{H})$, $0.93(\mathrm{t}, J=7.3 \mathrm{~Hz}, 3 \mathrm{H}), 0.67(\mathrm{~m}, 2 \mathrm{H}), 0.18(\mathrm{~d}, J=2.7$ $\mathrm{Hz}, 6 \mathrm{H}), 0.12$ (s, 6H).

Polystyrene- $b$-poly(vinylmethylsiloxane)

(PS-b-PVMS). To the mixture of sec-butyllithium hexane solution $(1.02 \mathrm{M}, 150 \mu \mathrm{L}, 153 \mu \mathrm{mol})$ and anhydrous THF $(3 \mathrm{~mL})$, styrene $(1 \mathrm{~mL}, 8.7 \mathrm{mmol})$ was added at $-40{ }^{\circ} \mathrm{C}$ under nitrogen atmosphere, to change the color of reaction mixture from pale yellow to bright orange. After stirring for $10 \mathrm{~min}$, the anhydrous THF (4 mL) solution of 1,3,5-trimethyl-1,3,5trivinylcyclotrisiloxane $(1.5 \mathrm{~mL}, 5.6 \mathrm{mmol})$ was added to the reaction mixture. After stirring for $16.5 \mathrm{~h}$, trimethylchlorosilane $(50 \mu \mathrm{L}, 390 \mu \mathrm{mol})$ was added to terminate polymerization, followed by additional stirring for $2.5 \mathrm{~h}$ to ensure the complete termination. After removal of the solvent under reduced pressure, the residue was purified by reprecipitation in methanol, to afford colorless powder $(1.4 \mathrm{~g}) . M_{\mathrm{N}}=36100$, $M_{\mathrm{W}} / M_{\mathrm{N}}=1.21 .{ }^{1} \mathrm{H}$ NMR $\left(\mathrm{CDCl}_{3}\right) \delta 7.05(\mathrm{~m}, 3 \times \mathrm{xH})$, $6.58(\mathrm{~m}, 2 \mathrm{xH}), 6.78-5.75(\mathrm{~m}, 3 \mathrm{yH}), 1.86-1.42(\mathrm{~m}, 3 \mathrm{xH})$, 0.14 (s, 3yH).

Polystyrene- $b$-poly(methylsiloxane) tethered by LC side chains (PS- $\boldsymbol{b}$-PMS(Stb)). To the mixture of PS-b-PVMS (100 mg) and platinum(0)-1,3-divinyl$1,1,3,3$-tetramethyldisiloxane in xylene $(2.2 \%, 20 \mu \mathrm{L}$, $1.2 \mu \mathrm{mol})$ and toluene $(0.5 \mathrm{~mL})$, the toluene $(0.5 \mathrm{~mL})$ solution of $3(210 \mathrm{mg})$ was added dropwise at $60{ }^{\circ} \mathrm{C}$ and heated for 4 days under nitrogen atmosphere. After the platinum catalyst was removed through the silica gel short column chromatography by using chloroform as eluent, the crude product was then purified by reprecipitation in methanol and sequential Soxhlet extraction with hexane, to give colorless powder (70 $\mathrm{mg}) . M_{\mathrm{N}}=52100, M_{\mathrm{W}} / M_{\mathrm{N}}=1.25 .{ }^{1} \mathrm{H} \mathrm{NMR}\left(\mathrm{CDCl}_{3}\right) \delta$ 7.34 (br, 4zH), 7.09-6.58 (br, $(5 \mathrm{x}+4 \mathrm{z}) \mathrm{H}), 5.95-5.76$ $(\mathrm{m}, 3 \mathrm{yH}), 3.84(\mathrm{~s}, 2 \mathrm{zH}), 2.56(\mathrm{~s}, 2 \mathrm{zH}), 2.17-1.06(\mathrm{~m}$, $(3 \mathrm{x}+6 \mathrm{z}) \mathrm{H}), 0.93-0.88(\mathrm{~m}, 3 \mathrm{zH}), 0.59(\mathrm{br}, 2 \mathrm{zH}), 0.45$ $(\mathrm{s}, 2 \mathrm{zH}), 0.07-0.04(\mathrm{t},(3 \mathrm{y}+6 \mathrm{z}) \mathrm{H})$.

\section{RESULTS AND DISCUSSION}

3.1 Synthesis of LC diblock copolymer

The main chain block copolymer PS-b-PVMS was synthesized via anionic polymerization of styrene followed by 1,3,5-trimethyl-1,3,5trivinylcyclotrisiloxane. A small aliquot of the reaction mixture was taken to confirm the consumption of styrene monomer before adding the cyclosiloxane monomer, and then precipitated in methanol. Using this sample, the molecular weight and distribution of PS segment was determined as $M_{\mathrm{N}}=32000$ and $M_{\mathrm{W}} / M_{\mathrm{N}}=1.28$ based on molecular standard samples of PS (Aldrich), respectively. The degree of polymerization (x) was determined as 308 from the $M_{\mathrm{N}}$ value.

The LC side chains were introduced via catalytic hydrosiliation of vinyl groups in the PVMS segment with the hydrodisiloxane units 3. As shown in Figure $1 \mathrm{~b}$, the GPC profile for the product was shifted higher molecular weight region than that of PS- $b$-PVMS. On the ${ }^{1} \mathrm{H}$ NMR spectrum of the product shown in Figure 1a, while the peaks at 5.95-5.76 ppm assigned as vinyl protons in the PVMS segment $\left(\mathrm{H}_{\mathrm{i}}\right)$ almost disappeared, a new peak assignable to protons $\left(\mathrm{H}_{\mathrm{j}}\right)$ on the carbon connecting with the disiloxane group in the side chain, suggesting the side chains were almost quantitatively introduced at vinyl groups in the PVMS segment. The numbers of repeated units for vinylmethylsiloxane units (y) and LC-tethered methylsiloxane units (z)

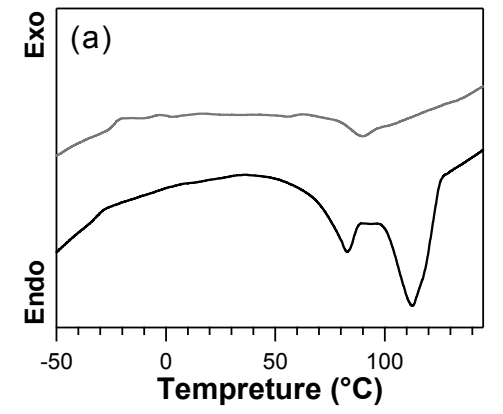

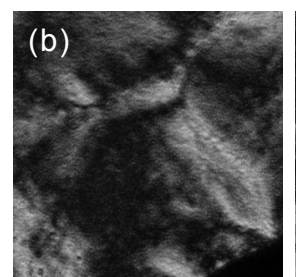
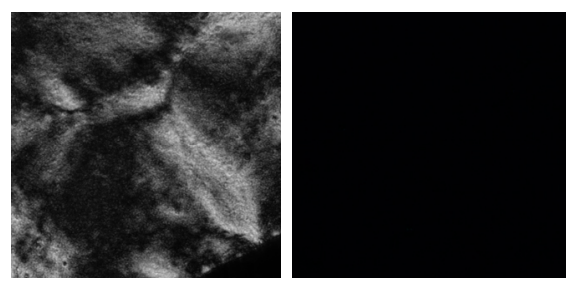

Figure 2 DSC curves (a) of PS-b-PVMS (gray) and LC block copolymer PS-b-PMS(Stb) (black line) together with POM images (b) of LC block copolymer at 80 (left), 101 (center) and $130^{\circ} \mathrm{C}$ (right). 


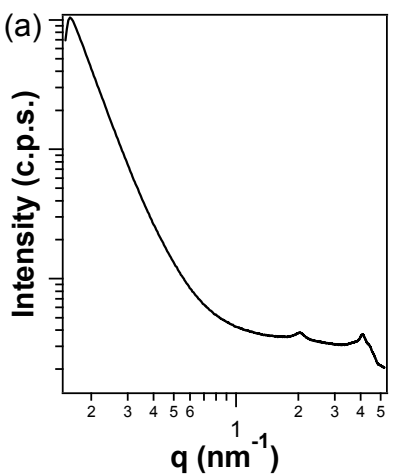

(b)

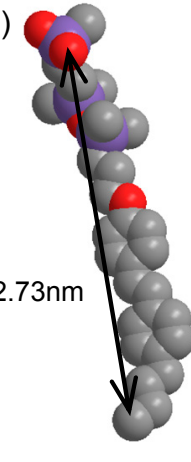

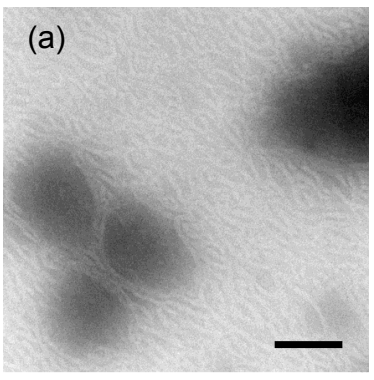

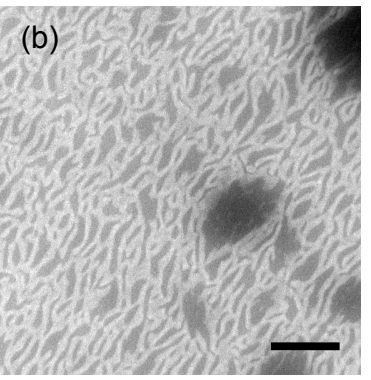

Figure 4 TEM images of PS-b-PMS(Stb) spin-coat films, unstained (a) and stained (b) by $\mathrm{RuO}_{4}$. The scale bars are of $500 \mathrm{~nm}$.

should be observed as dark region because of the relative high electron density of $\mathrm{Si}$. The contrast between PS and LC polymethylsiloxane domains in the TEM image were emphasized by staining using $\mathrm{RuO}_{4}$. Although the possibility of cylindrical assembles cannot be excluded, the weight fraction of polysiloxane segment including the LC side chain was calculated to be $55 \%$, which might be reasonable value for exhibiting lamellae structure from the Flory-Huggins theory.

\section{CONCLUSION}

The LC diblock copolymer PS-b-PMS(Stb) composed of a polystyrene and a polymethylsiloxane segment tethered by stilbene LC mesogens as the side chains was synthesized by the combination of anionic polymerization and catalytic hydrosilylation with keeping narrow polydisparsity. The LC diblock copolymer exhibited smectic LC phase, and gave a lamellae-like nanostructure in the thin films. Although the LC side chains were introduced in aiming to improve the regularity of the phase segregated nanostructure, the bulk sample of the block copolymer showed no periodicity on the SAXS profile.

\section{REFERENCES}

[1] C.-C. Chao, T.-C. Wang, R.-M. Ho, P. Georgopanos, A. Avgeropoulos, E. L. Thomas, ACS Nano, 4, 2088-94 (2010).

[2] Y. S. Jung, C. A. Ross, Nano Lett., 7, 2046-50 (2007).

[3] T. Hirai, M. Leolukman, C. C. Liu, E. Han, Y. J. Kim, Y. Ishida, T. Hayakawa, M.-a. Kakimoto, P. F. Nealey, P. Gopalan, Adv. Mater., 21, 4334-38 (2009).

[4] S. Asaoka, T. Uekusa, H. Tokimori, M. Komura, T. Iyoda, T. Yamada, H. Yoshida, Macromolecules, 44, 7645-58 (2011).

[5] Y. Tian, K. Watanabe, X. Kong, J. Abe, T. Iyoda, Macromolecules, 35, 3739-47 (2002).

[6] K. Aoki, T. Iwata, S. Nagano, T. Seki, Macromol. Chem. Phys., 211, 2484-89 (2010).

[7] A. Moment, R. Miranda, P. T. Hammond, Macromol. Rapid Commun., 19, 573-79 (1998).

[8] E. Verploegen, L. C. McAfee, L. Tian, D. Verploegen, P. T. Hammond, Macromolecules, 40, 777-80 (2007).

[9] E. Verploegen, T. Zhang, Y. S. Jung, C. Ross, P. T. Hammond, Nano Lett., 8, 3434-40 (2008).

(Received 31 January 2012; Accepted 28 April 2012) 